\title{
Influence of ionic liquids and concentration of red phosphorous on luminescent $\mathrm{Cu}_{3} \mathrm{P}$ nanocrystals
}

\author{
YOGENDRA NATH CHOURYAL, RAHUL KUMAR SHARMA, DEBOPAM ACHARJEE, \\ TRISIT GANGULY, ARCHNA PANDEY and PUSHPAL GHOSH* (D) \\ Department of Chemistry, School of Chemical Science and Technology, Dr. Harisingh Gour University \\ (A Central University), Sagar 470 003, Madhya Pradesh, India \\ E-mail: pushpalghosh27@gmail.com
}

MS received 31 March 2019; revised 9 May 2019; accepted 15 May 2019

\begin{abstract}
Highly crystalline, phase pure $\mathrm{Cu}_{3} \mathrm{P}$ nanocrystals (NCs) have been successfully synthesized using ionic liquid-assisted solvothermal method at relatively low temperature $\left(200{ }^{\circ} \mathrm{C}\right)$. Herein, ionic liquids (ILs) are used as a structure directing/templating agent. Effect of ILs and precursor concentration on crystal phase, crystallite size, lattice strain, morphology and grain size of $\mathrm{Cu}_{3} \mathrm{P}$ NCs is studied. In the presence of IL, crystallite size and lattice strain significantly change with changing the concentration of red phosphorus. For example, smaller crystallite size $(38.5 \mathrm{~nm})$ and compressive lattice strain are obtained when 10 times of red phosphorous is used. However, bigger size $(41.9 \mathrm{~nm})$ and tensile lattice strains are obtained for the lower concentration of phosphorous (5 times). At higher phosphorus concentration, hexagonal shaped microcrystals with prominent grain are observed. HRTEM images reveal that spherical-shaped particles on further agglomeration through Ostwald ripening process form hexagonal-shaped bigger microstructures. However, on doping the rare-earth ions $\left(\mathrm{RE}^{3+}=\mathrm{Ce}^{3+} / \mathrm{Tb}^{3+}\right)$ in the $\mathrm{Cu}_{3} \mathrm{P}$ NCs show the green luminescence (at $542 \mathrm{~nm}$ ) which is attributed to the emission of $\mathrm{Tb}^{3+}$ ions. To the best of our knowledge, this is the first report on rareearth doped $\mathrm{Cu}_{3} \mathrm{P}$ nanoparticles and shows promise on the luminescence aspect of $\mathrm{Cu}_{3} \mathrm{P}$ nanomaterials along with its already existing plasmonic and semiconducting properties.
\end{abstract}

Keywords. Nanocrystals; rare-earth; copper phosphide; photoluminescence; ionic liquids.

\section{Introduction}

Recently nanocrystalline transition metal phosphides have been emerged as a promising class of semiconducting nanomaterials for numerous applications. ${ }^{1-18}$ For instance, $\mathrm{CoP}, \mathrm{NiP}$ and $\mathrm{FeP}$ nanoparticles have been employed as a electrocatalyst for hydrogen evolution and lithium ion storage. ${ }^{3,4}$ However, CdP, InP and $\mathrm{Zn}_{3} \mathrm{P}_{2}$ nanoparticles have shown prominent optical properties leading to numerous optical applications such as photovoltaic, telecommunication and so on. ${ }^{5-10}$ Amongst those, copper phosphide $\left(\mathrm{Cu}_{3} \mathrm{P}\right)$ is selected due to various reasons which make it a promising candidate for optoelectronic applications due to having both the plasmonic and semiconducting properties. Copper is a very cheap element, non-toxic and has high natural abundance. In addition, $\mathrm{Cu}_{3} \mathrm{P}$ has dual properties; it can be used in high efficiency catalysis and also exhibits plasmonic property. ${ }^{19-22} \mathrm{As}$ a result, it is extensively employed for various applications including superconductivity, potential in magnetic recording media, anode materials in lithium ion battery, showing good electrochemical performances, light emitting, photovoltaic, oxygen reduction reaction, carbon dioxide reduction, methanol/ethanol oxidation, water splitting and so on. ${ }^{2,12-18} \mathrm{Cu}_{3} \mathrm{P} \mathrm{NCs}$ are P-type semiconducting nanomaterials with band gap of about 1.3-1.6 eV. Judicious choice or fabrication of synthesis protocols is utmost important to control the size of $\mathrm{Cu}_{3} \mathrm{P}$ NCs which will control the size dependent optical properties. ${ }^{19-21}$ Many researchers have synthesized $\mathrm{Cu}_{3} \mathrm{P}$ NPs at high

\footnotetext{
*For correspondence

Electronic supplementary material: The online version of this article (https://doi.org/10.1007/s12039-019-1665-y) contains supplementary material, which is available to authorized users.
} 
temperature using several methods. For examples, mechanochemical, solvothermal reactions, co-reaction using organometallic reagents with phosphines are employed which leads to different types of structural and optical properties. ${ }^{11,22-25}$ Most of the researchers have used $\mathrm{P}_{2} \mathrm{~S}_{5}$, yellow/red/white phosphorus, tricotyl phosphine (TOP) and phosphine gas as a phosphorous precursor. ${ }^{19-25}$

Doping of transition metal or rare-earth $\left(\mathrm{RE}^{3+}\right)$ ions in semiconducting nanomaterials is very interesting to obtain nanomaterials with desired properties including optical, photocatalytic activity, etc. ${ }^{26-29}$ There are numerous semiconducting nanomaterials like $\mathrm{ZnS}$, $\mathrm{In}_{2} \mathrm{~S}_{3}, \mathrm{GaN}$, etc. which have been used as host matrix for doping of $\mathrm{RE}^{3+}$ ions $\left(\mathrm{Er}^{3+}, \mathrm{Ce}^{3+}, \mathrm{Eu}^{3+}\right.$, etc.) for getting luminescent nanomaterials for various applications. $^{26-29}$ Interestingly, excitation and emission spectra of $\mathrm{RE}^{3+}$ doped luminescent nanomaterials are independent of size of host matrix due to confined $4 \mathrm{f}-$ 4f intraconfigurational transitions which are highly shielded by 5 s and 5 p orbitals. ${ }^{30-32}$ Till now, the literature related to $\mathrm{RE}^{3+}$ doped $\mathrm{Cu}_{3} \mathrm{P} \mathrm{NCs}$ is not reported to the best of our knowledge. $\mathrm{Cu}_{3} \mathrm{P}$ nanomaterials show semiconducting as well as plasmonic property. ${ }^{19}$ However, judicious doping of $\mathrm{RE}^{3+}$ ions in $\mathrm{Cu}_{3} \mathrm{P}$ NCs would increase its applications in visible region of solar spectra.

Normally, for the preparation of nanoparticles and tuning their crystal phase, morphology and band gap, amine-based capping/templating agents are being employed which have drastic impact on the environment. ${ }^{33-38}$ In this context, it has become an obligation to develop the environmentally benign synthesis protocols to design the nanoparticles with desired functions. So, IL-assisted synthesis of nanoparticles is getting tremendous attention. ${ }^{33-38}$ ILs usually possess organic/inorganic cation and inorganic anion moieties and having melting point below $100{ }^{\circ} \mathrm{C}$ in ambient conditions. By varying the alkyl chain length of cation, nature of cation (aromatic or non-aromatic) and anion, changing the cation-anion combination, concentration and viscosity, the physicochemical properties of ILs can be tuned which will further tune the structural and optical properties of nanomaterials. ${ }^{34-36}$ Thus, ILs are considered as a "green and designer solvent". In many cases, ILs are not only being employed as a capping/ templating agent, solvent but also can be used as a reaction partner too. ${ }^{11,33,34,38}$

Herein, we have successfully synthesized $\mathrm{Cu}_{3} \mathrm{P} \mathrm{NCs}$ using IL-assisted solvothermal method. Thereafter, influence of ILs and red phosphorus concentration on the crystal phase, lattice strain, and morphology of $\mathrm{Cu}_{3} \mathrm{P}$ NCs is studied. It is noticed that crystallite size is decreasing with phosphorus concentration in the presence of 1-ethyl-3-methylimidazolium bromide $\left(\left[\mathrm{C}_{2} \mathrm{mim}\right] \mathrm{Br}\right)$ IL. Lattice strain changes from tensile to compressive with increasing phosphorus concentration. Substantial effect of ILs is found on the morphology and grain boundary of $\mathrm{Cu}_{3} \mathrm{P} \mathrm{NCs}$. It is noticed that in case of ally-based IL, grain boundary is not so much prominent and surface is smoother than that of other ILs. Furthermore, on doping of $\mathrm{Ce}^{3+} / \mathrm{Tb}^{3+}$ ions in $\mathrm{Cu}_{3} \mathrm{P} \mathrm{NCs}$, emission is obtained in green region.

\section{Experimental}

\subsection{Chemicals}

Cuprous chloride [CuCl] (LobaChemie, 99.9\%), Red phosphorous [P] (LobaChemie, 99.9\%), 1-methylimidazolium $\left[\mathrm{C}_{4} \mathrm{H}_{6} \mathrm{~N}_{2}\right]$ (Alfa Aesar, 99\%), 1,2-dimethyl imidazole $\left[\mathrm{C}_{5} \mathrm{H}_{8} \mathrm{~N}_{2}\right]$ (Sigma Aldrich 99\%), Bromoethane $\left[\mathrm{C}_{2} \mathrm{H}_{5} \mathrm{Br}\right]$ (Himedia, 99\%), Bromobutane $\left[\mathrm{C}_{4} \mathrm{H}_{9} \mathrm{Br}\right]$ (Himedia, 99\%), Allyl bromide $\left[\mathrm{C}_{3} \mathrm{H}_{5} \mathrm{Br}\right]$ (Himedia, 99\%), Tetramethyl ammonium bromide $\left[\left(\mathrm{CH}_{3}\right)_{4} \mathrm{NBr}\right]$ (TMAB) (Himedia, 99\%), Ethyl acetate $\left[\mathrm{C}_{2} \mathrm{H}_{5} \mathrm{COOCH}_{3}\right]$ (LobaChemie, 99\%) Acetone $\left[\mathrm{C}_{3} \mathrm{H}_{6} \mathrm{O}\right]$, (LobaChemie, 99.5\%), Diethyl ether $\left[\left(\mathrm{C}_{2} \mathrm{H}_{5}\right)_{2} \mathrm{O}\right]$ (LobaChemie, 99\%), Deionized water $\left[\mathrm{H}_{2} \mathrm{O}\right](\mathrm{CDH})$.

\section{1a 1-ethyl-3-methyl imidazolium bromide [ $\mathrm{C}_{2} \mathrm{mim}$ ]} $\mathrm{Br}$ : Modifying a literature procedure, 1-ethyl-3-methylimidazolium bromide $\left[\mathrm{C}_{2} \mathrm{mim}\right] \mathrm{Br}$ is synthesized by incorporation of $12.4 \mathrm{~mL}$ bromoethane $\left[\mathrm{C}_{2} \mathrm{H}_{5} \mathrm{Br}\right]$, and $10 \mathrm{~mL} \mathrm{~N}$-methyimidazole $\left[\mathrm{C}_{4} \mathrm{H}_{6} \mathrm{~N}_{2}\right]$ and refluxed in a round bottom flask $(250 \mathrm{~mL})$ at $40{ }^{\circ} \mathrm{C}$ for $4 \mathrm{~h}$ in an inert gas (Ar) atmosphere. After the completion of reaction, the obtained product was washed with ethyl acetate $\left[\mathrm{C}_{4} \mathrm{H}_{8} \mathrm{O}_{2}\right]$ and stirred for $1 \mathrm{~h}$. Then it was filtered and dried in vacuum for $12 \mathrm{~h}$ to get a white solid. ${ }^{39}$

\section{1b 1-Ethyl-1,2-dimethylimidazolium bromide $\left[C_{2}\right.$} dmim]Br: Modifying a literature procedure, 1 , 2-dimethyl-imidazolium, $\left[\mathrm{C}_{2} \mathrm{dmim}\right] \mathrm{Br}$ is synthesized by mixing of $53.82 \mathrm{~mL}$ of 1,2-dimethyl imidazole, and 58.91 $\mathrm{mL}$ of bromoethane and then refluxed in a round bottom flask $(250 \mathrm{~mL})$ under inert atmosphere at $40{ }^{\circ} \mathrm{C}$ for $3 \mathrm{~h}$. After the completion of reaction, the obtained product was washed with ethyl acetate and stirred for $1 \mathrm{~h}$. Then it was filtered and dried in vacuum for $12 \mathrm{~h}$ to get a white solid. ${ }^{40}$

\section{1c 1-Allyl-3-methylimidazolium bromide [Amim]}

$\mathrm{Br}$ : Modifying a literature procedure, 1-allyl-3-methylimidazolium bromide $\left[\mathrm{C}_{7} \mathrm{H}_{11} \mathrm{BrN}_{2}\right]$ is synthesized by mixing $\mathrm{N}$-methyimidazole $\left[\mathrm{C}_{4} \mathrm{H}_{6} \mathrm{~N}_{2}\right]$ and allyl bromide $\left[\mathrm{C}_{3} \mathrm{H}_{5} \mathrm{Br}\right]$, and then refluxed in a round bottom flask $(250 \mathrm{~mL})$ under inert atmosphere at $40{ }^{\circ} \mathrm{C}$ for $3 \mathrm{~h}$. After the completion of reaction, the obtained product was washed with ethyl 
acetate and stirred for $1 \mathrm{~h}$. Then it was filtered and dried in vacuum for $12 \mathrm{~h}$ to get a white solid. ${ }^{40}$

\subsection{Synthesis of $\mathrm{Cu}_{3} \mathrm{P}$ NCs}

First judicious amount of ILs (for example, $0.5 \mathrm{~g}$ $\left.\left[\mathrm{C}_{2} \mathrm{mim}\right] \mathrm{Br}\right)$, Cuprous chloride $(0.669 \mathrm{~g})$ and Red phosphorous $(0.0698 \mathrm{~g})$ are mixed with deionized water. Then the solution is stirred at room temperature for $5 \mathrm{~min}$ and the mixture was poured into a Teflon lined autoclave and heated at $200{ }^{\circ} \mathrm{C}$ for $14 \mathrm{~h}$. When the autoclave was cooled to room temperature in ambient condition, the black product was centrifuged (2000 rpm for $10 \mathrm{~min}$ ) and was washed with water and diethyl ether to remove the other impurities. And the final black product was dried in a hot air oven for $12 \mathrm{~h}$.

\subsection{Synthesis of doped $\mathrm{Cu}_{3} \mathrm{P}: \mathrm{Ce}^{3+} / \mathrm{Tb}^{3+} \mathrm{NCs}$}

Here we have synthesized $\mathrm{Cu}_{3} \mathrm{P}: \mathrm{Ce}^{3+} / \mathrm{Tb}^{3+} \mathrm{NCs}$ using the above-mentioned method for undoped $\mathrm{Cu}_{3} \mathrm{P}$ NCs. Here only Cerium nitrate $(0.0099 \mathrm{~g})$ and Terbium nitrate $(0.0100 \mathrm{~g})$ are mixed along with Copper and Phosphorus precursors. Thereafter, as-obtained particles are washed using the same procedure.

\subsection{Characterizations}

PXRD was carried out on a D8 Advance BRUKER, equipped with $\mathrm{Cu}-\mathrm{K} \alpha(1.54060 \AA)$ as the incident radiation. The crystallite size was calculated using Scherer equation $\mathrm{D}=\mathrm{K} \lambda / \beta \cos \theta$, where $\mathrm{D}$ represents crystallite size $(\AA), \mathrm{K}=$ $0.9, \lambda$ is the wavelength of $\mathrm{Cu}-\mathrm{K} \alpha$ radiation and $\beta$ is the corrected half width of the diffraction peak. Morphological characterization was also carried out by SEM using a NOVA NANO SEM-450, FEI. TEM (FEI Tecnai STWINT30 using $200 \mathrm{kV}$ electron beam source) was used to map the shape, size and lattice structure of the NCs dispersed on a carbon-coated copper grid from acetone solution. Photoluminescence emission and excitation spectra were measured through HORIBA JOBIN YVON made Fluoromax-4 spectrofluorometer.

\section{Result and Discussion}

\subsection{Structural analysis using PXRD}

3.1a Effect of reaction temperature and reaction time: First different synthesis parameters like reaction temperature and reaction time are tuned to optimize the synthesis for $\mathrm{Cu}_{3} \mathrm{P}$ nanoparticles (Figure 1). Here, the concentration of phosphorous is taken 5 times more than its stoichiometric

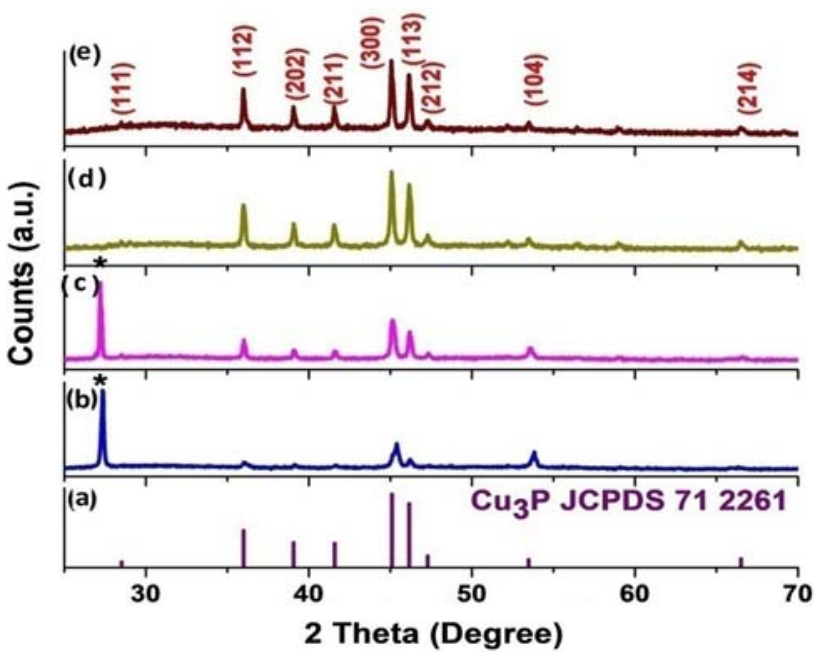

Figure 1. PXRD patterns of $\mathrm{Cu}_{3} \mathrm{P}$ NCs: (a) Standard $\mathrm{Cu}_{3} \mathrm{P}$, (b) prepared in presence of $\left[\mathrm{C}_{2} \mathrm{mim}\right] \mathrm{Br}$, at $150{ }^{\circ} \mathrm{C}$ for $24 \mathrm{~h}$ reaction time; (c) prepared in presence of $\left[\mathrm{C}_{2} \mathrm{mim}\right] \mathrm{Br}$, at $200{ }^{\circ} \mathrm{C}$ for $9 \mathrm{~h}$ reaction time; (d) prepared without IL at $200{ }^{\circ} \mathrm{C}$ for $14 \mathrm{~h}$, and (e) prepared in presence of $\left[\mathrm{C}_{2} \mathrm{mim}\right] \mathrm{Br}$, at $200{ }^{\circ} \mathrm{C}$ for $14 \mathrm{~h}$ reaction time. All are prepared using 5 times phosphorus.

concentration in all cases. When the synthesis is performed at $150{ }^{\circ} \mathrm{C}$ for $24 \mathrm{~h}$ in the presence of $\left[\mathrm{C}_{2} \mathrm{mim}\right] \mathrm{Br} \mathrm{IL}$, there is no formation of phase pure $\mathrm{Cu}_{3} \mathrm{P}$ NCs (Figure $\left.1 \mathrm{~b}\right)$. Impurity at lower angle $(2 \theta=$ 27.23) is observed due to presence of unreacted cuprous chloride (shown by asterisk *). This indicates that the reaction is not completed at $150{ }^{\circ} \mathrm{C}$. Thereafter, reaction temperature is increased to $200{ }^{\circ} \mathrm{C}$ and reaction time is gradually increased to 9 , 14 and $24 \mathrm{~h}$. Similar impurity of unreacted cuprous chloride (shown by asterisk *) is observed for the synthesis occured at $200{ }^{\circ} \mathrm{C}$ for $9 \mathrm{~h}$ (Figure 1c). Phase pure $\mathrm{Cu}_{3} \mathrm{P} \mathrm{NCs}$ are obtained from $14 \mathrm{~h}$ reaction time at $200{ }^{\circ} \mathrm{C}$ (Figure $1 \mathrm{~d}$, e). All peaks are nicely matching with JCPDS card no. 71-2261. For the remaining reactions, reaction temperature and time are set to $200{ }^{\circ} \mathrm{C}$ and $14 \mathrm{~h}$ respectively (shown in Table 1). No change in crystal phase of NCs is noticed. However, crystallite size is considerably changed. For example, bigger crystallite size (ca. $49.9 \mathrm{~nm}$ ) is obtained in absence of IL in comparision to that of NCs $(41.9 \mathrm{~nm})$ which are synthesized using $\mathrm{IL}\left(\left[\mathrm{C}_{2} \mathrm{mim}\right] \mathrm{Br}\right)$, under similar experimental conditions (Figure 1d, e and Table 1). This clearly indiactes that IL is working as a capping agent or templating agent in the nanoparticle synthesis.

3.1b Effect of phosphorous concentration: Like reaction temperature and reaction time, concentration of phosphorous has also significant effect in 
Table 1. $\mathrm{Cu}_{3} \mathrm{P}$ NCs, their reaction time, reaction temperature, phosphorous concentration, particle size and their lattice strain.

\begin{tabular}{llcccccl}
\hline $\begin{array}{l}\text { Sample } \\
\text { code* }\end{array}$ & $\begin{array}{c}\text { Ionic liquid } \\
(\mathrm{IL} 1 \%)\end{array}$ & $\begin{array}{c}\text { Reaction } \\
\text { time }(\mathrm{h})\end{array}$ & $\begin{array}{c}\text { Reaction } \\
\text { temperature }\left({ }^{\circ} \mathrm{C}\right)\end{array}$ & $\begin{array}{c}\text { Conc. } \\
(\mathrm{P}) *\end{array}$ & $\begin{array}{c}\text { Particle size } \\
(\mathrm{nm})\end{array}$ & $\begin{array}{c}\text { Lattice } \\
\text { strain }(\%)\end{array}$ & Tensile/compressive \\
\hline $\mathrm{CP} 1$ & $\mathrm{NO}$ & 14 & 200 & $5 \mathrm{P}$ & 49.9 & 9.22 & Tensile \\
$\mathrm{CP} 2$ & {$\left[\mathrm{C}_{2} \mathrm{mim}\right] \mathrm{Br}$} & 14 & 200 & $5 \mathrm{P}$ & 41.9 & 5.95 & Tensile \\
$\mathrm{CP} 3$ & {$\left[\mathrm{C}_{2} \mathrm{mim}\right] \mathrm{Br}$} & 14 & 200 & $10 \mathrm{P}$ & 38.5 & -3.02 & Compressive \\
CP4 & {$[\mathrm{Amim}] \mathrm{Br}$} & 14 & 200 & $5 \mathrm{P}$ & 49.3 & 6.72 & Tensile \\
CP5 & TMAB & 14 & 200 & $5 \mathrm{P}$ & 45.8 & 6.88 & Tensile \\
CP6 & {$\left[\mathrm{C}_{2} \mathrm{dmim}\right] \mathrm{Br}$} & 14 & 200 & $5 \mathrm{P}$ & 45.1 & 7.59 & Tensile \\
\hline
\end{tabular}

${ }^{*} \mathrm{CP}=\mathrm{Cu}_{3} \mathrm{P}, \mathrm{P}=$ phosphorous concentration.

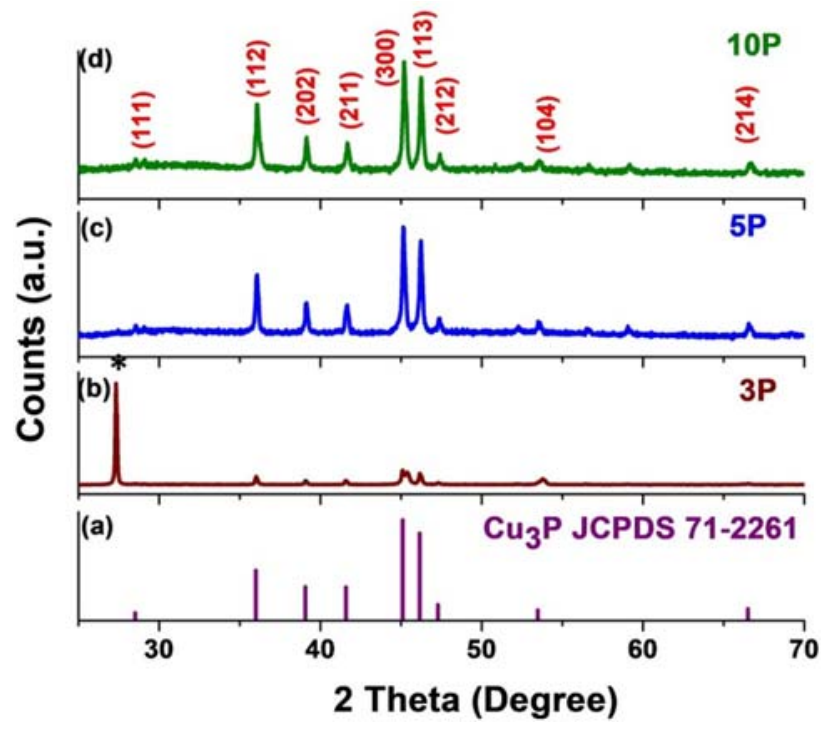

Figure 2. PXRD patterns of $\mathrm{Cu}_{3} \mathrm{P}$ NCs: (a) Standard $\mathrm{Cu}_{3} \mathrm{P}$ JCPDS Card, (b) prepared with 3 times phosphorus concentration at $200{ }^{\circ} \mathrm{C}$ for $24 \mathrm{~h},(\mathbf{c})$ prepared with 5 times phosphorus concentration at $200{ }^{\circ} \mathrm{C}$ with $14 \mathrm{~h}$, and (d) prepared with 10 times phosphorus concentration at $200{ }^{\circ} \mathrm{C}$ for $14 \mathrm{~h}$. In all cases $\left[\mathrm{C}_{2} \mathrm{mim}\right] \mathrm{Br}$ IL is used.

nanoparticle formation (Figure 2). No phase pure $\mathrm{Cu}_{3} \mathrm{P}$ nanoparticles are formed till 3 times phosphorus concentration (Figure 2b). In this case, unreacted $\mathrm{CuCl}$ is obtained as impurity which is indicated by asterisk (*). However phase pure $\mathrm{Cu}_{3} \mathrm{P}$ nanoparticles with cubic phase are observed when 5 times phosphorous is used at $200{ }^{\circ} \mathrm{C}$ and with $14 \mathrm{~h}$ reaction time (Figure 2c). When phosphorous concentration is increased to 10 times, no change in crystals phase is observed (Figure 2d). However, significant effect on crystallite size of the $\mathrm{Cu}_{3} \mathrm{P}$ NCs under the similar conditions is noticed. Crystallite size is gradually decreasing with increasing the phosphorus concentration. For instance, 41.9 and $38.5 \mathrm{~nm}$ crystallite size is obtained for 5 and 10 folds red phosphorus concentration respectively under the similar reaction conditions. From this, it is clearly evident that concentration of red phosphorus has significant impact on the purity and crystallite size of as-obtained NCs.

3.1c Effect of ionic liquids (ILs): After studying the influence of phosphorus concentration, role of different ionic liquids (ILs) such as $\left[\mathrm{C}_{2} \mathrm{mim}\right] \mathrm{Br}$, $\left[\mathrm{C}_{2} \mathrm{dmim}\right] \mathrm{Br}$, [Amim] Br, and TMAB are studied (Figure 3). Here, we have tuned ILs by substituting the acidic proton situated at $\mathrm{C}-2$ position, alkyl group at C-1 position (ethyl, allyl) and taking IL with nonaromatic system (tetramethylammonium ion). Then it is studied how these influence on the crystal phase, crystallite size of the $\mathrm{Cu}_{3} \mathrm{P}$ NCs. It is noticed that the

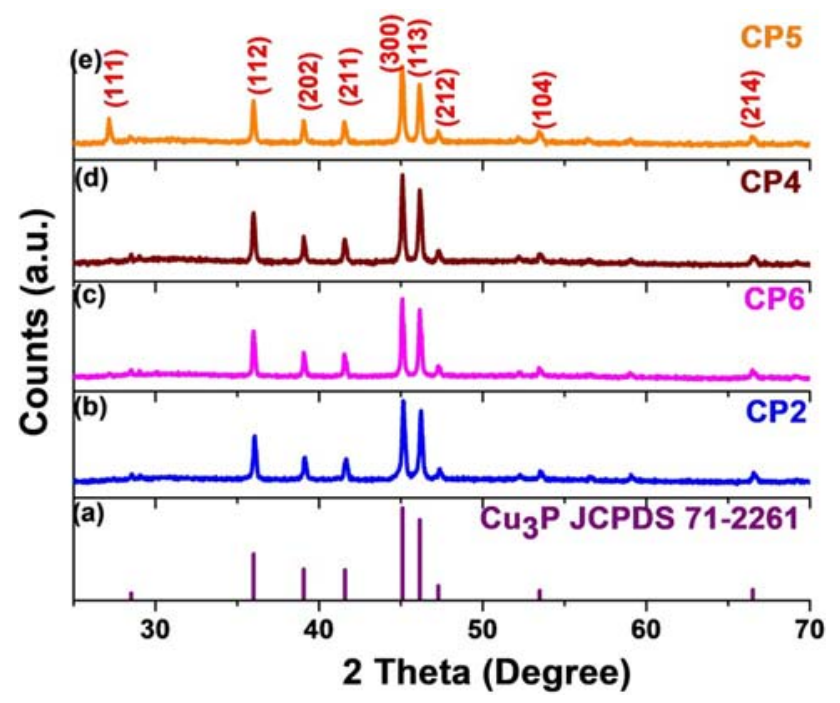

Figure 3. PXRD patterns of $\mathrm{Cu}_{3} \mathrm{P}$ NCs: (a) Standard $\mathrm{Cu}_{3} \mathrm{P}$ JCPDS Card, (b) prepared in presence of $\left[\mathrm{C}_{2} \mathrm{mim}\right] \mathrm{Br}$, (c) prepared in presence of $\left[\mathrm{C}_{2} \mathrm{dmim}\right] \mathrm{Br}$, (d) prepared in presence of $[\mathrm{Amim}] \mathrm{Br}$ and (e) prepared in presence of TMAB. All are synthesized using 5 times phosphorus and in the presence of different ILs $(1 \%)$ at $200^{\circ} \mathrm{C}$ and $14 \mathrm{~h}$. 
crystal phase is same in all the cases. But there is a change in the crystallite size. For example, when $\left[\mathrm{C}_{2} \mathrm{mim}\right] \mathrm{Br}$ is used, $41.9 \mathrm{~nm}$ is noticed for the crystallite size. Here it can be anticipated that binding to the nanoparticle site can occur through aromatic $\pi$ system or $\mathrm{H}$ bonding. To confirm this, we have used $\left[\mathrm{C}_{2} \mathrm{dmim}\right] \mathrm{Br}$ where $\mathrm{H}$ at $\mathrm{C}-2$ position is replaced by a methyl group and crystallite size is noticed increasing $(45.1 \mathrm{~nm})$. So it gives a clear indication that along with aromatic $\pi$ system, hydrogen bonding is also playing an important role.

When [Amim]Br is used (Figure 3d), $49.3 \mathrm{~nm}$ is observed for crystallite size which is bigger than the $\left[\mathrm{C}_{2} \mathrm{mim}\right] \mathrm{Br}$. This clearly indicates that due to bigger size allyl group in $\mathrm{C}-1$ position, IL cation facing steric hindrance compared to $\left[\mathrm{C}_{2} \mathrm{mim}\right] \mathrm{Br}$ analogue. Similarly $45.8 \mathrm{~nm}$ crystallite size is obtained when IL with non-aromatic system like TMAB is used (Figure $3 \mathrm{e}$ ). Our study confirms that binding of ionic liquids at the nucleation site of $\mathrm{Cu}_{3} \mathrm{P}$ is very important to obtain nanoparticles of desired crystallite site.

\subsection{Lattice strain}

Normally, lattice strain varies with changing the crystallite size of NCs. This can be rationalized using the Williamson-Hall equation which can be expressed as:

$\beta \cos \theta / \lambda=1 / D+\eta \sin \theta / \lambda$

where $\beta$ is the full width at half-maximum (FWHM), $\theta$ is the diffraction angle, $\lambda$ is the $\mathrm{X}$-ray wavelength, $D$ is the effective crystallite size and $\eta$ is the effective strain. On plotting graph between $\beta \cos \theta / \lambda$ vs $\sin \theta / \lambda$, the lattice strain can be determined from the slope. The positive and negative magnitudes of the slope infer the tensile and compressive strain respectively.

Lattice strain results clearly show that by varying the concentration of red phosphorus, tensile strain is decreasing and then render to compressive strain (Figure $4 \mathrm{a}, \mathrm{e})$. For instance, when 5 times phosphorus concentration is used, tensile strain $(5.95 \%)$ is found (Figure $4 \mathrm{a}$ ). On the other hand, on increasing the concentration of phosphorus to 10 folds, lattice strain is changed to compressive strain $(-3.02 \%)$ [shown in Figure 4e]. These changes can be illustrated on the basis of crystallite size. Interestingly, in the presence of $\left[\mathrm{C}_{2} \mathrm{mim}\right] \mathrm{Br}$ IL, when 10 folds concentration of red phosphorus was employed, smallest crystallite size (i.e. $38.5 \mathrm{~nm}$ ) is found. In other

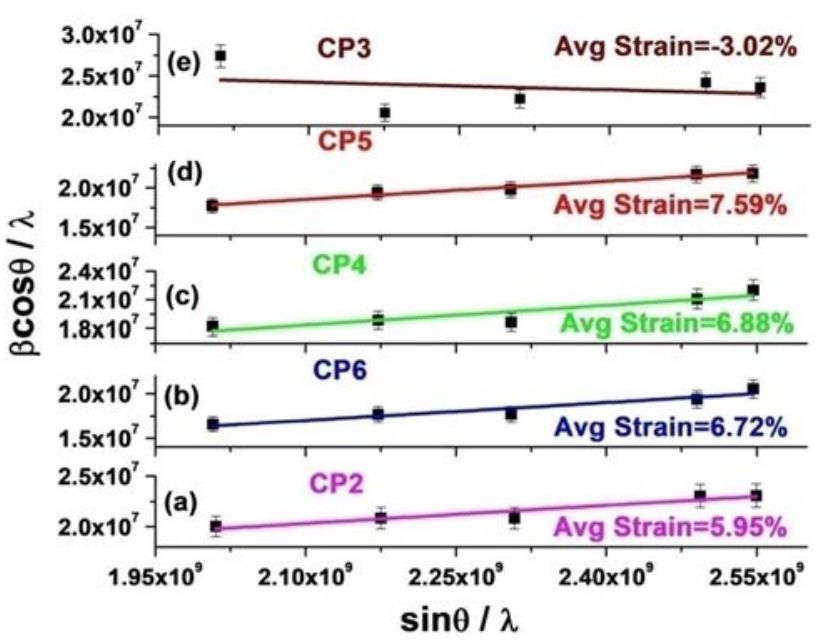

Figure 4. Lattice strain of as-prepared $\mathrm{Cu}_{3} \mathrm{P}$ NCs: (a) 5 times phosphorus with $\left[\mathrm{C}_{2}\right.$ mim]Br IL, (b) 5 times phosphorus with $\left[\mathrm{C}_{2} \mathrm{dmim}\right] \mathrm{Br}$ IL, (c) 5 times phosphorus with [Amim]Br IL, (d) 5 times phosphorus with TMAB IL and (e) 10 times phosphorus with $\left[\mathrm{C}_{2} \mathrm{mim}\right] \mathrm{Br}$ IL. All are synthesized using (1\%) IL at $200{ }^{\circ} \mathrm{C}$ for $14 \mathrm{~h}$.

words, this size can be attributed to critical size of $\mathrm{Cu}_{3} \mathrm{P}$ NCs from where compressive strain is observed. Maximum value of tensile strain (9.22\%) is obtained for the $\mathrm{Cu}_{3} \mathrm{P} \mathrm{NCs}$ which are synthesized using no IL (Figure S1, Supplementary Information). However, value of tensile strain is found less for sample which is synthesized using IL than that of sample synthesized without IL. It means, ILs are serving as capping agent. Interestingly, on changing the alkyl chain length, removing acidic proton situated at C-2 position of imidazolium cation and changing the nature of cation from aromatic cation (imidazolium) to non-aromatic (tetramethylammonium) cation of IL, significant influence on lattice strain is observed. Tensile strain gradually increases with changing the ILs (Figure 4a-d).

\subsection{Morphology analysis by scanning electron microscopy}

Figure 5 depicts the FESEM images of as-prepared $\mathrm{Cu}_{3} \mathrm{P} \mathrm{NCs}$ at different concentration of phosphorus and ILs which are synthesized using solvothermal method. These images illustrate that bigger size of particles with prominent grain is occurring in the absence of IL while the particles are comparatively smaller and having less prominent grain boundary in the presence of $\left[\mathrm{C}_{2} \mathrm{mim}\right] \mathrm{Br} \mathrm{IL}$, prepared under the same reaction condition (shown in Figure 5a, b). And morphology of $\mathrm{Cu}_{3} \mathrm{P} \mathrm{NCs}$ is irregular shaped. However, when the 

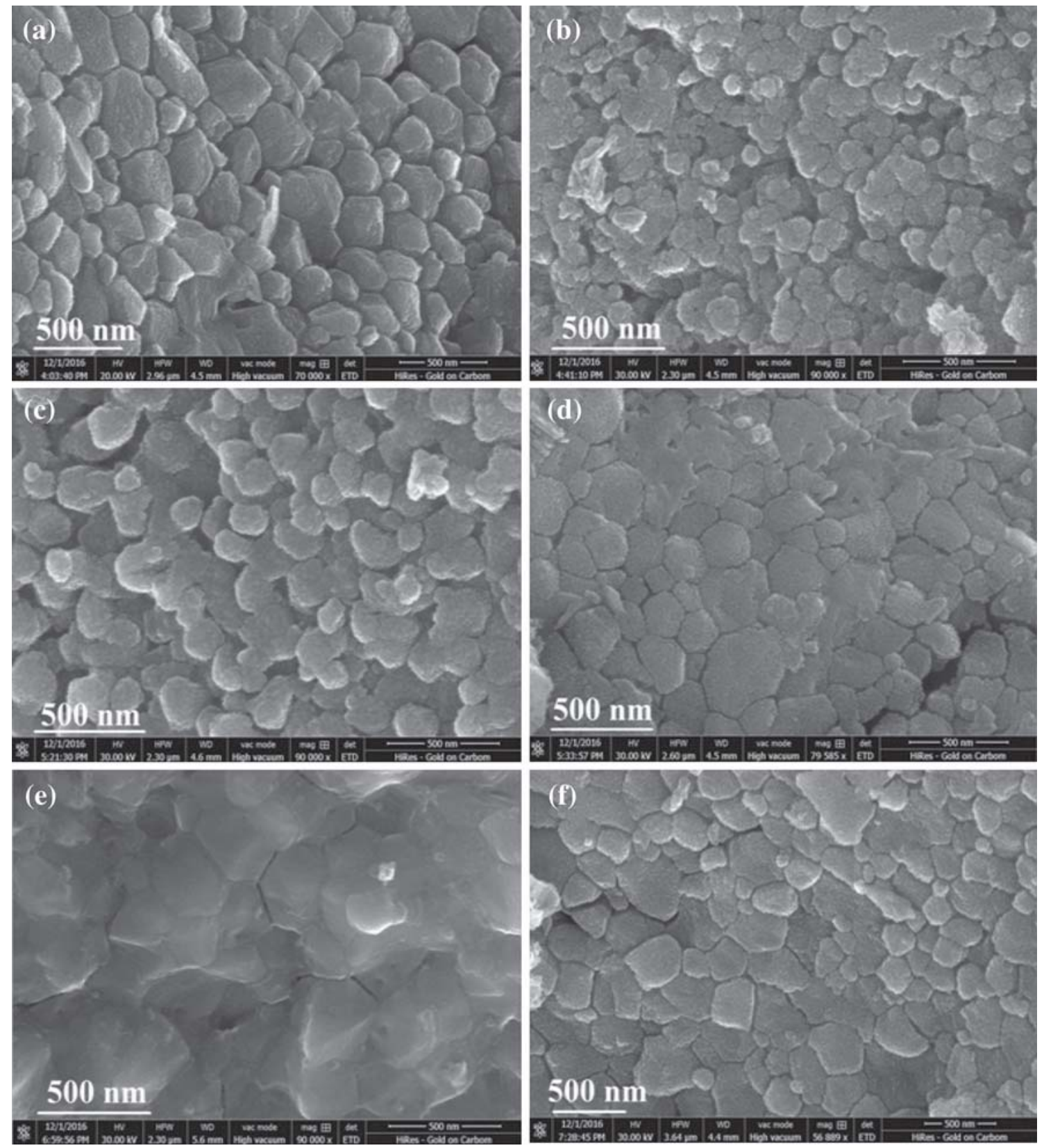

Figure 5. FESEM images of $\mathrm{Cu}_{3} \mathrm{P}$ NCs: (a) 5 times phosphorus without IL, (b) 5 times phosphorus with $\left[\mathrm{C}_{2} \mathrm{mim}\right] \mathrm{Br}$ IL, (C) 10 times phosphorus with $\left[\mathrm{C}_{2} \mathrm{mim}\right] \mathrm{Br} \mathrm{IL}$, (d) 5 times phosphorus with $\left[\mathrm{C}_{2} \mathrm{dmim}\right] \mathrm{Br}$, (e) 5 times phosphorus with [Amim]Br IL and (f) 5 times phosphorus with TMAB IL which are synthesized at $200{ }^{\circ} \mathrm{C}$ for $14 \mathrm{~h}$.

concentration of red phosphorus increased to 10 folds, remarkable change in morphology is observed, not only the grain boundary is changing but also shape of $\mathrm{Cu}_{3} \mathrm{P} \mathrm{NCs}$ is becoming to regular hexagonal-shaped particles (Figure 5c). In other words, hexagonal shape can be further confirmed by finding the numbers of particles present around the centre particle. For instance, each central particle is surrounded with six different particles as can be seen in Figure 5d. It means each particle is coordinated with six different particles resulting in appearance of hexagonal shape. In the case of [Amim]Br, grain boundary is not clear and surface of particles is smoother compared to the particles which are synthesized using other ILs or without IL (shown in Figure 5e and S2E).

From Figure $5 \mathrm{f}$ and $\mathrm{S} 2 \mathrm{~F}$, it is seen that mainly pentagonal nanoagglomerate is observed when TMAB is used. Above analysis clearly reveals that ILs have a considerable impact on morphology of the as-prepared $\mathrm{Cu}_{3} \mathrm{P}$ NCs. High magnification FESEM images of these samples are shown in Figure S2, Supplementary Information. 

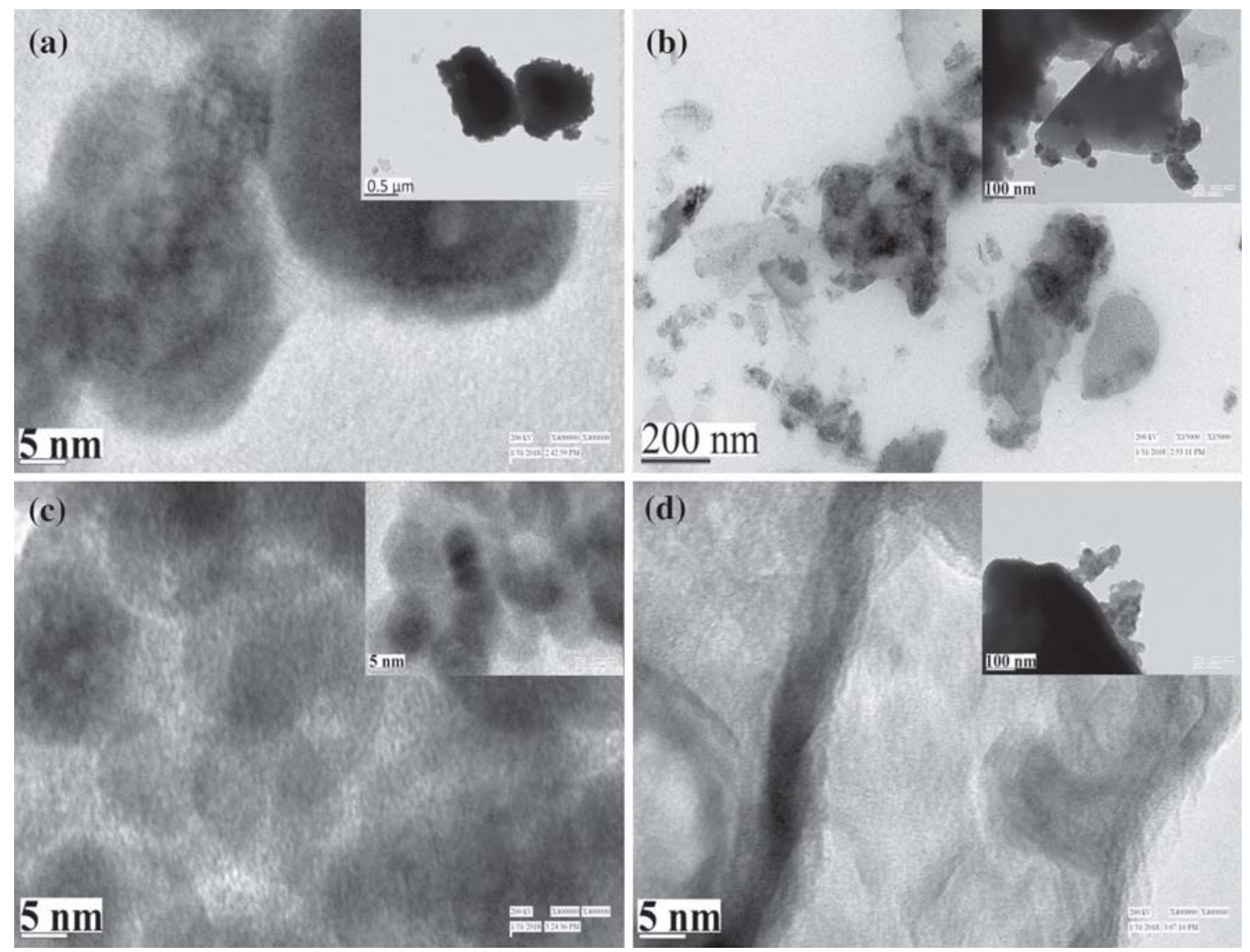

Figure 6. High resolution and low (inset) resolution TEM images of as-prepared $\mathrm{Cu}_{3} \mathrm{P}$ NCs: (a) without IL, (b) with $\left[\mathrm{C}_{2} \mathrm{mim}\right] \mathrm{Br}$, (c) with [Amim] $\mathrm{Br}$ and $(\mathbf{d})$ with TMAB. All samples are prepared using 5 times phosphorus with different ILs $(1 \%)$ at $200{ }^{\circ} \mathrm{C}$ for $14 \mathrm{~h}$.

\subsection{Morphology analysis by transmission electron microscopy}

To get more insight about the growth of particles at nanoscale, low magnification and HRTEM images are analyzed (Figure 6). These images are basically made up of spherical-shaped particles, which are on further agglomeration through Ostwald ripening leading to form hexagonal-shaped bigger microstructures (Scheme 1).

It has been seen that, particles are more agglomerated in the absence of IL than that of NCs which are prepared in the presence of IL (Scheme 1 and Figure 6a, b). Being spherical and easily disturbed with electron beam during measurement, apparently it was difficult to see lattice fringes. Interestingly, it has been noticed that in the absence and presence of IL except TMAB, particles seem more or less spherical (Figure 6a-c). On the other hand, in presence of TMAB, particles have not prominent shape (Figure 6d). At the same time, spherical nanoparticles are obtained when [Amim]Br is used (Figure 6c). It is clearly noticed that radius of the spherical nanoparticles will be $10-15 \mathrm{~nm}$.

\subsection{Energy Dispersive X-ray analysis (EDX)}

To confirm whether the dopant ions $\left(\mathrm{Ce}^{3+}\right.$ and $\left.\mathrm{Tb}^{3+}\right)$ are properly incorporated in the $\mathrm{Cu}_{3} \mathrm{P} \mathrm{NCs}$ or not, EDX of as-prepared $\mathrm{Ce} / \mathrm{Tb}$ co-doped $\mathrm{Cu}_{3} \mathrm{P} \mathrm{NCs}$ is measured. EDX result clearly shows that $\mathrm{Ce}^{3+}$ and $\mathrm{Tb}^{3+}$ ions are nicely incorporated in the $\mathrm{Cu}_{3} \mathrm{P}$ NCs (Figure 7).

\subsection{Optical property}

Along with pure and undoped $\mathrm{Cu}_{3} \mathrm{P} \mathrm{NCs}, \mathrm{RE}^{3+}$ ions ( $\mathrm{Ce}$ and $\mathrm{Tb}$ ) doped $\mathrm{Cu}_{3} \mathrm{P} \mathrm{NCs}$ are also prepared. Figure 8a, b depict the excitation and emission spectra of $\mathrm{Ce} / \mathrm{Tb}$ co-doped $\mathrm{Cu}_{3} \mathrm{P}$ NCs which are prepared using $\left[\mathrm{C}_{2} \mathrm{mim}\right] \mathrm{Br} \mathrm{IL}$ at $200{ }^{\circ} \mathrm{C}$. As-prepared $\mathrm{Cu}_{3} \mathrm{P}: \mathrm{Ce} /$ $\mathrm{Tb}$ NCs are black powder. So there is a significant challenge to get good emission. On exciting the $\mathrm{Ce}^{3+}$ doped $\mathrm{Cu}_{3} \mathrm{P}$ NCs at $278 \mathrm{~nm}$, broad emission peak around $340-380 \mathrm{~nm}$ appears which corresponds to $5 \mathrm{~d}-$ 4f transition of $\mathrm{Ce}^{3+}$ ion (Figure $\mathrm{S} 3 \mathrm{a}, \mathrm{b}$, Supplementary Information). ${ }^{30,31}$ Figure $8 \mathrm{a}$ shows the 


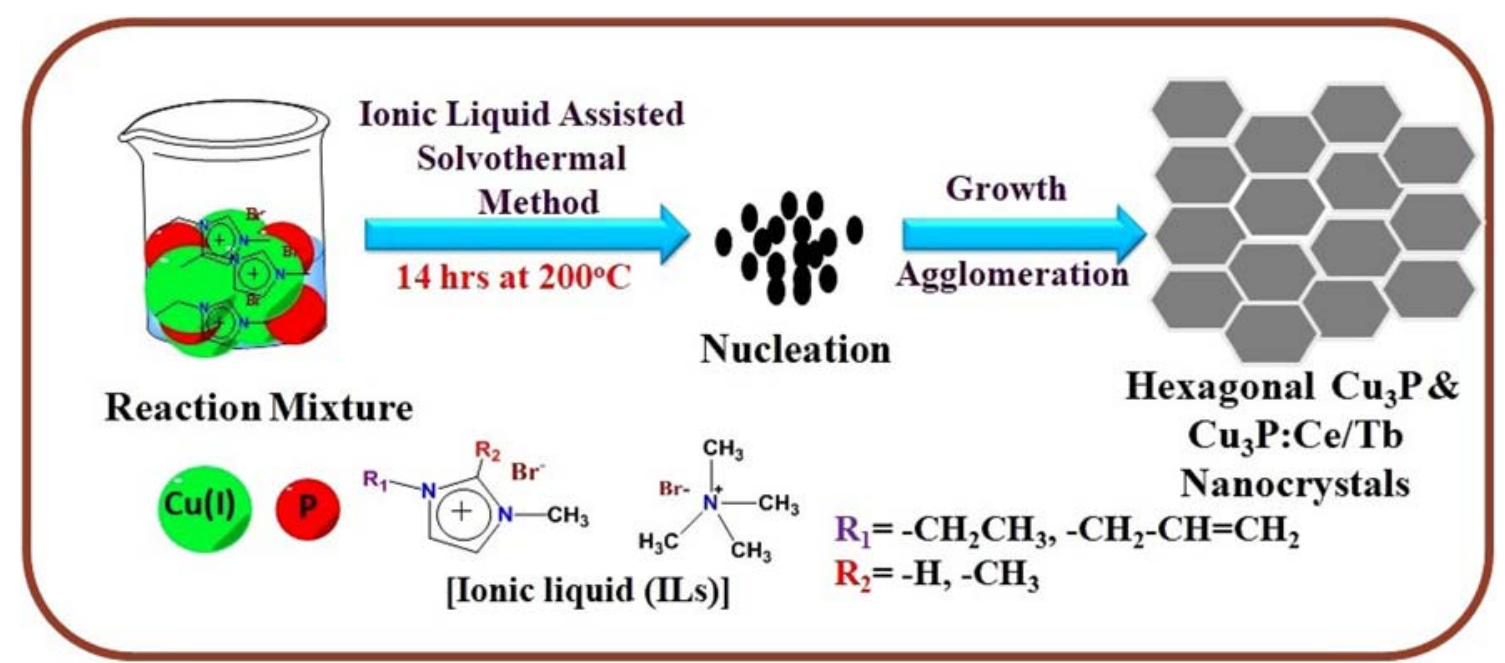

Scheme 1. Schematic representation of synthesis of $\mathrm{Cu}_{3} \mathrm{P}$ and $\mathrm{Ce} / \mathrm{Tb}$ co-doped $\mathrm{Cu}_{3} \mathrm{P}$ nanocrystals in presence of ionic liquids.

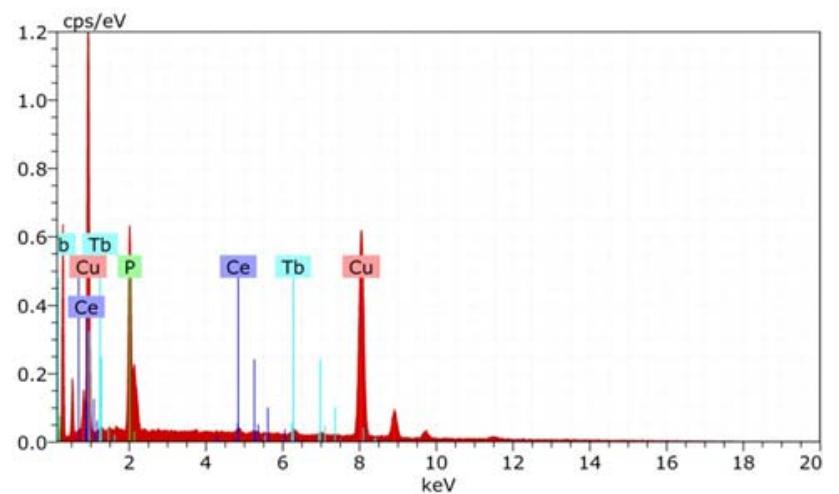

Figure 7. $\mathrm{EDX}$ of as-prepared $\mathrm{Ce} / \mathrm{Tb}$ co-doped $\mathrm{Cu}_{3} \mathrm{P} \mathrm{NCs}$ synthesized using 5 times phosphorus with $\left[\mathrm{C}_{2} \mathrm{mim}\right] \mathrm{Br} \mathrm{IL}$ at $200{ }^{\circ} \mathrm{C}$ and $14 \mathrm{~h}$.

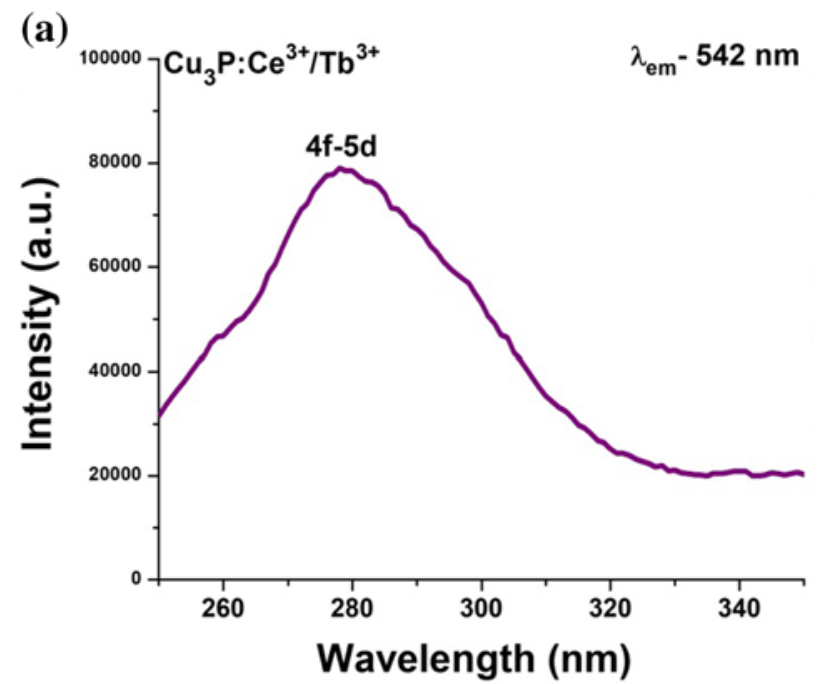

excitation spectra of $\mathrm{Ce}^{3+}$ and $\mathrm{Tb}^{3+}$ co-doped $\mathrm{Cu}_{3} \mathrm{P}$ NCs being monitored at $542 \mathrm{~nm}$. Appearance of peak at $278 \mathrm{~nm}$ is due to $4 \mathrm{f}-5 \mathrm{~d}$ transition. ${ }^{30,31}$ On exciting at $278 \mathrm{~nm}$, normally energy transfer is taking place from $\mathrm{Ce}^{3+}$ to $\mathrm{Tb}^{3+}$ ions. ${ }^{30,31}$

Thereafter, non-radiative decay occurs to the excited level ${ }^{5} \mathrm{D}_{4}$ of $\mathrm{Tb}^{3+}$ ions followed by radiative decay to numerous underlying levels ${ }^{7} \mathrm{~F}_{0-6}$ of $\mathrm{Tb}^{3+}$ ions. As a result, characteristic emission peaks of $\mathrm{Tb}^{3+}$ ion at 482 , 542,585 and $621 \mathrm{~nm}$ correspond to ${ }^{5} \mathrm{D}_{4}-{ }^{7} \mathrm{~F}_{6},{ }^{5} \mathrm{D}_{4}-{ }^{7} \mathrm{~F}_{5}$, ${ }^{5} \mathrm{D}_{4}-{ }^{7} \mathrm{~F}_{4}$ and ${ }^{5} \mathrm{D}_{4-}{ }^{7} \mathrm{~F}_{3}$ transitions, respectively are found in $\mathrm{Cu}_{3} \mathrm{P}: \mathrm{Ce} / \mathrm{Tb} \mathrm{NCs}$ (shown in Figure 8b)..$^{30,31}$ The highly intense green emission is observed at $542 \mathrm{~nm}\left({ }^{5} \mathrm{D}_{4}-{ }^{7} \mathrm{~F}_{5}\right.$ transition $)$ which is regarded as magnetic dipole transition of $\mathbf{J}= \pm 1$ (Figure $8 b$ ). ${ }^{30,31}$

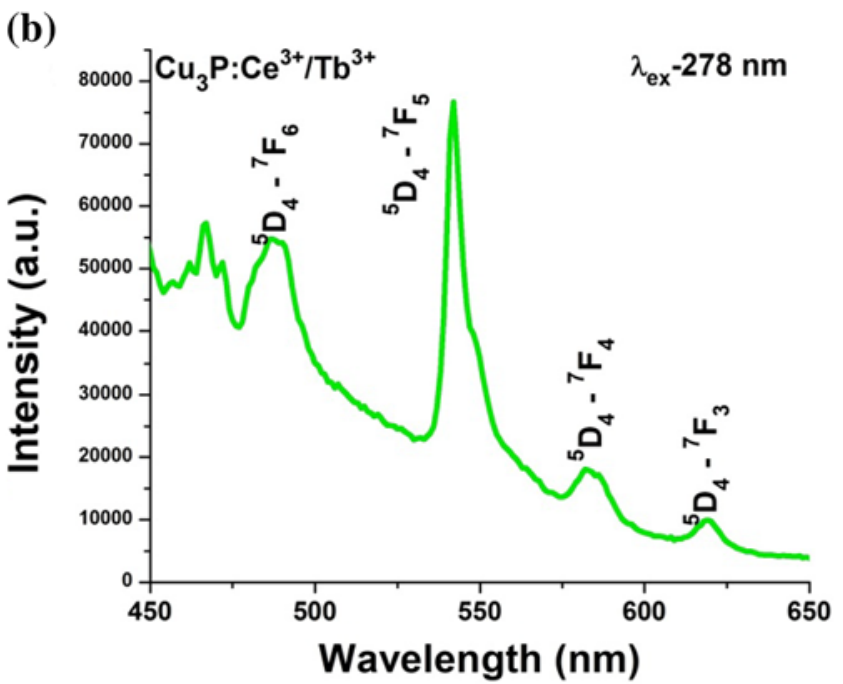

Figure 8. Photoluminescence spectra of as-prepared $\mathrm{Ce}^{3+}$ and $\mathrm{Tb}^{3+}$ co-doped $\mathrm{Cu}_{3} \mathrm{P}$ NCs: $\left(\right.$ a) excitation spectrum $\left[\lambda_{\mathrm{em}}=\right.$ $542 \mathrm{~nm}]$ and $(\mathbf{b})$ emission spectrum $\left[\lambda_{\mathrm{ex}}=278 \mathrm{~nm}\right]$. This sample is synthesized using 5 times phosphorus with $\left[\mathrm{C}_{2} \mathrm{mim}\right] \mathrm{Br}$ $\mathrm{IL}$ at $200{ }^{\circ} \mathrm{C}$ for $14 \mathrm{~h}$. 


\section{Conclusions}

In summary, we have successfully synthesized $\mathrm{Cu}_{3} \mathrm{P}$ NCs using ILs assisted solvothermal approach. Herein ILs are employed as structure directing agent. Analysis reveals that ILs, reaction temperature, concentration of red phosphorous and reaction time has significant effect on crystallite size, lattice strain and morphology of $\mathrm{Cu}_{3} \mathrm{P}$ NCs. Crystallite size is decreased on sequentially increasing the phosphorus concentration. Consequently, lattice strain is also changed from tensile to compressive when high phosphorous concentration is used. However, crystallite size of as-prepared $\mathrm{Cu}_{3} \mathrm{P}$ NCs is found less in the presence of ILs compared to the NCs synthesized without IL. In addition, morphology is also significantly changed in the presence of IL and concentration of phosphorus. Shape of $\mathrm{Cu}_{3} \mathrm{P}$ NCs gradually changes from spherical to hexagonal or pentagonal-shaped. Furthermore, we have successfully doped the $\mathrm{Ce}$ and $\mathrm{Ce} / \mathrm{Tb}$ ions in $\mathrm{Cu}_{3} \mathrm{P} \mathrm{NCs}$ which is further confirmed through EDX analysis. As a result, green emission is found on exciting the $\mathrm{Ce} / \mathrm{Tb}$-doped $\mathrm{Cu}_{3} \mathrm{P}$ NCs. This emission is attributed to energy transfer process which is taking place from $\mathrm{Ce}^{3+}$ to $\mathrm{Tb}^{3+}$ ion. This result confirms that other rare-earth ions can also be incorporated inside $\mathrm{Cu}_{3} \mathrm{P}$ NCs which may enhance the applications aspects of $\mathrm{Cu}_{3} \mathrm{P}$ NCs. Along with its interesting semiconducting and plasmonic properties, $\mathrm{Cu}_{3} \mathrm{P}$ nanomaterials can be used as luminescent materials also when they are doped with judiciously chosen rare-earth ions. For example, by doping with $\mathrm{Er}^{3+} / \mathrm{Yb}^{3+}$ ions in $\mathrm{Cu}_{3} \mathrm{P}$ host lattice, efficient upconverting materials can be obtained. However by doping with $\mathrm{Gd}^{3+} / \mathrm{Eu}^{3+}$ ions, quantum cutting materials useful for energy efficient lighting may be obtained. In addition, understanding the band gap and photoluminescence properties of $\mathrm{Cu}_{3} \mathrm{P}$ nanomaterials is very much important to explore various important applications.

\section{Supplementary Information (SI)}

Lattice strain of $\mathrm{Cu}_{3} \mathrm{P}$ NCs synthesized using 5 times phosphorus, without $\mathrm{IL}$ and at $200{ }^{\circ} \mathrm{C}$ for $14 \mathrm{~h}$ (Figure S1). FESEM images of as-prepared $\mathrm{Cu}_{3} \mathrm{P}$ NCs: A) 5 times phosphorus without IL, B) 5 times phosphorus with $\left[\mathrm{C}_{2}\right.$ $\operatorname{mim}] \mathrm{Br}, \mathrm{C}) 10$ times phosphorus with $\left[\mathrm{C}_{2} \operatorname{mim}\right] \mathrm{Br}$, D) 5 times phosphorus with $\left.\left[\mathrm{C}_{2} \mathrm{dmim}\right] \mathrm{Br}, \mathrm{E}\right) 5$ times phosphorus with $[\mathrm{Amim}] \mathrm{Br}$, and F) 5 times phosphorus with $\mathrm{TMAB}$ which are prepared at $200{ }^{\circ} \mathrm{C}$ for $14 \mathrm{~h}$ (Figure S2). Photoluminescence spectra of as-prepared $\mathrm{Ce}$ doped $\mathrm{Cu}_{3} \mathrm{P}$ NCs: (a) excitation measured at $\lambda_{\mathrm{em}}=372 \mathrm{~nm}$ and (b) emission at $\lambda_{\mathrm{ex}}=278 \mathrm{~nm}$ synthesized using 5 times phosphorus with $\left[\mathrm{C}_{2} \mathrm{mim}\right] \mathrm{Br}$ IL at $200{ }^{\circ} \mathrm{C}$ and $14 \mathrm{~h}$ (Figure S3,
Supplementary Information) are available at www.ias.ac.in/ chemsci.

\section{Acknowledgements}

The authors would like to acknowledge for financial support from the Science and Engineering Research Board (SERB) and Board of Research in Nuclear Sciences (BRNS), Government of India. The authors acknowledge Sophisticated Instrumentation Centre (SIC) for SEM, and Department of Chemistry for PXRD analysis. The authors also acknowledge the AIIMS New Delhi for TEM characterization support from PURSE programme sanctioned by Department of Science and Technology (DST), Govt of India.

\section{References}

1. Callejas J F, Read C G, Roske C W, Lewis N S and Schaak R E 2016 Synthesis, characterization, and properties of metal phosphide catalysts for the hydrogen-evolution reaction Chem. Mater. 286017

2. Wei K, Qi K, Jin Z, Cao J, Zheng W, Chen H and Cui X 2016 One-step synthesis of a self-supported copper phosphide nanobush for overall water splitting ACS Omega 11367

3. Du H, Kong R-M, Guo X, Qu F and Li J 2018 Recent progress in transition metal phosphides with enhanced electrocatalysis for hydrogen evolution Nanoscale 10 21617

4. Sun M, Liu H, Qu J and Li J 2016 Earth-rich transition metal phosphide for energy conversion and storage Adv. Energy Mater. 131600087

5. Miao S, Hickey S G, Rellinghaus $B$, Waurisch $C$ and Eychmüller A 2010 Synthesis and characterization of cadmium phosphide quantum dots emitting in the visible red to near-infrared J. Am. Chem. Soc. 1325613

6. Greuters J and Rizvi N 2003 UV laser micromachining of silicon, indium phosphide and lithium niobate for telecommunications applications. In: Thomas J. Glynn (ed.), Proceedings of SPIE Opto-Ireland 2002: Optics and photonics technologies and applications Vol. 4876

7. Luber E J, Mobarok M H and Buriak J M 2013 Solution-processed zinc phosphide $\left(\alpha-\mathrm{Zn}_{3} \mathrm{P}_{2}\right)$ colloidal semiconducting nanocrystals for thin film photovoltaic applications ACS Nano 78136

8. Bhushan $\mathrm{M}$ and Catalano A 1981 Polycrystalline $\mathrm{Zn}_{3-}$ $\mathrm{P}_{2}$ Schottky barrier solar cells Appl. Phys. Lett. 3839

9. Bachmann K J 1981 Properties, preparation, and device applications of indium phosphide Аnпи. Rev. Mater. Sci. 11441

10. Bera D, Qian L, Tseng T K and Holloway P H 2010 Nanocrystals for thin film photovoltaic applications quantum dots and their multimodal applications: a review Materials 32260

11. Wolff A, Pallmann J, Boucher R, Weiz A, Brunner E, Doert T and Ruck M 2016 Resource-efficient highyield ionothermal synthesis of microcrystalline $\mathrm{Cu}_{3-\mathrm{x}} \mathrm{P}$ Inorg. Chem. 558844 
12. Hao J, Yang W, Huang Z and Zhang C 2016 Superhydrophilic and superaerophobic copper phosphide microsheets for efficient electrocatalytic hydrogen and oxygen evolution Adv. Mater. Interfaces 31600236

13. Shen R, Xie J, Ding Y, Liu S-y, Adamski A, Chen X and $\mathrm{Li} \mathrm{X} 2019$ Carbon nanotube-supported $\mathrm{Cu}_{3} \mathrm{P}$ as high-efficiency and low-cost cocatalysts for exceptional semiconductor-free photocatalytic $\mathrm{H}_{2}$ evolution ACS Sustain. Chem. Eng. 73243

14. Kong M, Song $\mathrm{H}$ and Zhou J 2018 Metalorganophosphine framework-derived N,P-codoped carbon-confined $\mathrm{Cu}_{3} \mathrm{P}$ nanopaticles for superb $\mathrm{Na}$-ion storage Adv. Energy Mater. 81801489

15. Hua S, Qu D, An L, Jiang W, Wen Y, Wang $X$ and Sun Z 2019 Highly efficient p-type $\mathrm{Cu}_{3} \mathrm{P} / \mathrm{n}$-type $\mathrm{g}-\mathrm{C}_{3} \mathrm{~N}_{4}$ photocatalyst through Z-scheme charge transfer route Appl. Catal. B 240253

16. Zheng H, Huang X, Gao H, Lu G, Dong W and Wang G $2019 \mathrm{Cu} @ \mathrm{Cu}_{3} \mathrm{P}$ Core-shell nanowires attached to nickel foam as high-performance electrocatalysts for the hydrogen evolution reaction Chem. Eur. J. 251083

17. Wang R, Dong X-Y, Du J, Zhao J-Y and Zang S-Q 2018 MOF-Derived Bi-functional $\mathrm{Cu}_{3} \mathrm{P}$ nanoparticles coated by a N, P-Co-doped carbon shell for hydrogen evolution and oxygen reduction Adv. Mater. 301703711

18. Wolff A, Doert T, Hunger J, Kaiser M, Pallmann J, Reinhold R, Yogendra S, Giebeler L, Sichelschmidt J, Schnelle W, Whiteside R, Gunaratne H Q N, Nockemann P, Weigand J J, Brunner E and Ruck M 2018 Low-temperature tailoring of copper-deficient $\mathrm{Cu}_{3-\mathrm{x}} \mathrm{P}-$ electric properties, phase transitions, and performance in lithium-ion batteries Chem. Mater. 307111

19. Manna G, Bose R and Pradhan N 2013 Semiconducting and plasmonic copper phosphide platelets Angew. Chem. 1256894

20. Kristensen A, Yang J K, Bozhevolnyi S I, Link S, Nordlander P, Halas N J and Mortensen N A 2017 Plasmonic colour generation Nat. Rev. Mater. 216088

21. De Trizio L, Gaspari R, Bertoni G, Kriegel I, Moretti L, Scotognella $F$ and Marras S $2015 \quad \mathrm{Cu}_{3-\mathrm{x}} \mathrm{P}$ nanocrystals as a material platform for near-infrared plasmonics and cation exchange reactions Chem. Mater. 271120

22. Stan M C, Klöpsch R, Bhaskar A, Li J, Passerini S and Winter $\mathrm{M} 2013 \mathrm{Cu}_{3} \mathrm{P}$ binary phosphide: synthesis via a wet mechanochemical method and electrochemical behavior as negative electrode material for lithium-ion batteries Adv. Energy Mater. 3231

23. Barry B M and Gillan E G 2008 Low-temperature solvothermal synthesis of phosphorus-rich transitionmetal phosphides Chem. Mater. 202618

24. Wang X, Han K, Gao Y, Wan F and Jiang K 2007 Fabrication of novel copper phosphide $\left(\mathrm{Cu}_{3} \mathrm{P}\right)$ hollow spheres by a simple solvothermal method J. Cryst. Growth $\mathbf{3 0 7} 126$

25. Liu J, Meyns M, Zhang T, Arbiol J, Cabot A and Shavel A 2018 Triphenylphosphite as the phosphorus source for the scalable and cost-effective production of transition metal phosphides Chem. Mater. 301799

26. Bol A A, van Beek R and Meijerink A 2002 On the incorporation of trivalent rare earth ions in II-VI semiconductor nanocrystals Chem. Mater. 141121

27. Chen W, Bovin J O, Joly A G, Wang S g, Su F and Li G 2004 Full-color emission from $\operatorname{In}_{2} \mathrm{~S}_{3}$ and $\operatorname{In}_{2} \mathrm{~S}_{3}: \mathrm{Eu}^{3+}$ nanoparticles J. Phys. Chem. B 10811927

28. Hu H and Zhang W 2006 Synthesis and properties of transition metals and rare-earth, metals doped $\mathrm{ZnS}$ nanoparticles Opt. Mater. 28536

29. Kenyon A J 2002 Recent developments in rare-earth doped materials for optoelectronics Prog. Quantum Electron. 26225

30. Sharma R K, Mudring A-V and Ghosh P 2017 Recent trends in binary and ternary rare-earth fluoride nanophosphors: How structural and physical properties influence optical behavior J. Lumin. 18944

31. Ghosh P, Sharma R K, Chouryal Y N and Mudring A-V 2017 Size of the rare-earth ions: a key factor in phase tuning and morphology control of binary and ternary rare-earth fluoride materials $R S C A d v .733467$

32. Ghosh P and Patra A 2005 Understanding the influence of nanoenvironment on luminescence of rare-earth ions PRAMANA J. Phys. 65901

33. Dahl J A, Maddux B L S and Hutchison J E 2007 Toward greener nanosynthesis Chem. Rev. 1072228

34. Sharma R K, Chouryal Y N, Chaudhari S, Saravanakumar J, Dey S R and Ghosh P 2017 Adsorptiondriven catalytic and photocatalytic activity of phase tuned $\operatorname{In}_{2} \mathrm{~S}_{3}$ nanocrystals synthesized via ionic liquids ACS Appl. Mater. Interfaces 911651

35. Weingärtner H 2008 Understanding ionic liquids at the molecular level: facts, problems, and controversies Angew. Chem. Int. Ed. 47654

36. Marsh K N, Boxall J A and Lichtenthaler R 2004 Room temperature ionic liquids and their mixtures-a review Fluid Phase Equilib. 21993

37. Sharma R K, Nigam S, Chouryal Y N, Nema S, Bera S P, Bhargava Y and Ghosh P 2019 Eu-Doped $\mathrm{BaF}_{2}$ nanoparticles for bioimaging applications ACS Appl. Nano Mater. 2927

38. Sharma R K, Chouryal Y N, Nigam S, Saravanakumar J, Barik S and Ghosh P 2018 Tuning the crystal phase and morphology of the photoluminescent indium sulphide nanocrystals and their adsorption-based catalytic and photocatalytic applications ChemistrySelect 3 8171

39. Parnham E R, Slawin A M Z and Morris R E 2007 Ionothermal synthesis of $\beta-\mathrm{NH}_{4} \mathrm{AlF}_{4}$ and the determination by single crystal X-ray diffraction of its room temperature and low temperature phases J. Solid State Chem. 18049

40. Arco S D, Laxamana R T, Giron O D and Obliosca J M 2009 Synthesis of [RMIM] acetate halogen-free ionic liquids for use as greener solvents in Diels-Alder reaction Philipp. J. Sci. 138133 